\title{
Drug Carriers With Star Polymer Structures
}

\author{
L. KOTRCHOVÁ ${ }^{1}$, L. KOSTKA ${ }^{1}$, T. ETRYCH ${ }^{1}$ \\ ${ }^{1}$ Institute of Macromolecular Chemistry of the Czech Academy of Sciences, Prague, Czech \\ Republic
}

Received May 24, 2018

Accepted June 28, 2018

\section{Summary}

In this review we summarize several synthetic approaches to the advanced synthesis of star-like polymer-based drug carriers. Moreover, their application as nanomedicines for therapy or the diagnosis of neoplastic diseases and their biodistribution are reviewed in detail. From a broad spectrum of star-like systems, we focus only on fully water-soluble systems, mainly based on poly(ethylene glycol) or $\mathrm{N}$-(2-hydroxypropyl)methacrylamide polymer and copolymer arms and polyamidoamine dendrimers serving as the core of the star-like systems.
\end{abstract}

\section{Key words}

Water-soluble polymers - Drug carriers - Star polymers • Hyperbranched polymers

\section{Corresponding author}

L. Kostka, Department of Biomedicinal Polymers, Institute of Macromolecular Chemistry of the Czech Academy of Sciences, Heyrovského nám. 2, 16206 Prague 6, Czech Republic. E-mail: kostka@imc.cas.cz

\section{Introduction}

Generally, conventional treatment with low-molecular drugs presents a number of limits, which include unfavorable body distribution and strong side effects in healthy organs, thus preventing their use in more efficient therapies. The main drawbacks of the vast majority of drugs include their hydrophobicity and, thus, low solubility in physiological environments, non-specific biodistribution, which results in toxicity to healthy organs and cells, and the rapid elimination from the organism. Within the last three decades, significant efforts have been focused on the design and study of systems that enable the limitations of low-molecularweight drugs to be overcome using so-called drug delivery systems (DDSs). Various DDSs based on micelles, liposomes, polymerosomes or water-soluble polymers were studied extensively and some of them even reached preclinical and clinical stages of development. Water-soluble polymer carriers are one of the most studied systems among DDSs for the controlled delivery of active molecules. The attachment of drugs to the water-soluble polymeric carriers via covalent bonds significantly reduces the toxicity of the carried drug during transportation in the body and also prevents undesirable accumulation in healthy organs, thus minimizing the side effects of the carried drug. Another great advantage of water-soluble biocompatible polymers in controlled drug delivery is the significantly prolonged circulation time of the bound drug in the bloodstream from minutes up to several weeks (Etrych et al. 2012). The use of water-soluble polymer drug carriers should guarantee the safe transportation of pharmaceutical compounds to the site of interest. In the case of solid tumors, the main driving force for passive accumulation in neoplastic tissue is the enhanced permeability and retention effect (EPR), as described by Maeda and Matsumura (1989). The EPR takes advantage of the highly permeable neo-vasculature of tumor tissue and missing or undeveloped lymphatic drainage. The most widely studied polymers usually used as drug carriers are based on poly(ethylene glycol) (PEG) and the copolymers $N$-(2-hydroxypropyl)methacrylamide (pHPMA), poly(2oxazolines), etc. (Lidický et al. 2016, Pola et al. 2016, Chytil et al. 2015, Ulbrich et al. 2016, Li and Wallace 2008). The effectiveness of polymeric drug conjugates is determined not only by the chemical composition of the 
polymer or copolymer (monomers, functional groups), but also by their supramolecular arrangement in the solution. Several polymer structures (Jones et al. 2016) have been described in the literature, e.g. linear, diblock, graft, branched, hyperbranched and star-like polymers. (Hrubý et al. 2016) Polymers that are to be used as a drug carrier have to contain appropriate, functional groups suitable for active molecule bonding and, after fulfilling the role of a carrier, should be excreted from the organism. The polymer carriers can be eliminated from the body when the molecular weight and hydrodynamic radius $\left(R_{\mathrm{h}}\right)$, respectively, are below the renal threshold or their biodegradability ensures that degradation products with an $R_{\mathrm{h}}$ below the renal threshold are obtained. The EPR described above is strongly dependent on the size and $R_{\mathrm{h}}$, of the DDS. It was reported that polymeric systems with higher $R_{\mathrm{h}}$ (star-like polymers or micelles) show a superior EPR when compared to linear polymers (Ulbrich et al. 2016). In general, typical $R_{\mathrm{h}}$ for linear polymers is $4-6 \mathrm{~nm}$ and $R_{\mathrm{h}}$ of star-like systems or micelles is in range $10-20 \mathrm{~nm}$. Due to the greatly increased EPR and the possibility of incorporation of biodegradable spacers, some of the most studied and promising carrier structures for anticancer therapy are star-like and hyperbranched polymers.

Star-like polymers consist of at least three polymer arms connected to one branching point, called the core. Various types of star-like polymers can be found in the literature. They can vary in the composition of the polymer arms (homopolymer star, block copolymer star or statistical copolymer star), in the type of polymer arm attached to one core (miktoarm star) or in the core structure. Several review papers on the synthesis of star polymers and individual star-shaped polymers have recently been published (Lapienis 2009, Wu et al. 2015, Ren et al. 2016, Abbina et al. 2017). In the present review, we summarize fully water-soluble star-like polymer carriers based on hydrophilic polymers. The main attention is devoted to systems designed for cancer treatment. We split this review into two parts. In the first part, we focus on the synthetic aspects of star-like systems, while the second part is an overview of star-like systems from a biological and application point of view.

\section{Star-like polymer carrier synthesis}

Generally, there are two main synthetic approaches that are taken to prepare star-like polymer carriers using synthetic polymers. The first approach, which represents the majority of published works, is called grafting-onto. The second approach, called core-first or grafting-from, can also be found in literature, but represents only a minority of published works. In the corefirst strategy, a multifunctional core with functional groups modified by an initiator is used as the multifunctional initiator for polymerization to obtain polymer arms growing directly on the core. In the grafting-onto approach, linear semitelechelic polymers, synthesized in advance, are used for controlled grafting using end groups of these polymers with a functional group on the multifunctional core, thus creating a star-like structure. Nowadays, the synthesis of star-like polymer carriers via core-first or grafting-onto strategies is based on commercially available or pre-synthesized multifunctional cores so as to form starlike polymers. Examples of the most common commercially available cores used for star-like carrier synthesis include non-biodegradable poly(amidoamine) dendrimers (PAMAM) (Wang et al. 2000, Etrych et al. 2011a), multifunctional alcohols such as pentaerytritol and dipentaerytritol, and biodegradable polyesters based on 2,2'-bis(hydroxy-methyl)propionic acid (bis-MPA). Structures of these cores are shown in Figure 1.

The third approach taken to synthesize star-like polymers is the arm-first method. In this case, pre-synthesized linear polymers are cross-linked by a multifunctional coupling agent at the polymer chain end. For example, Learsch et al. used a ring-opening metathesis polymerization technique for the cross-linking reaction of pre-synthesized polymeric arms. They used various derivatives of dinorbornenes as cross-linking agents (Learsch and Miyake 2018).

In general, based on the above-described approaches, star-like systems can be sorted into 12 groups, as schematically summarized in Figure 2 (Ren et al. 2016).

Star-like polymer systems can be classified according to the composition and sequence distribution of the polymer arms into homopolymer stars, block copolymer stars or statistical copolymer stars. The second division is based on the variability of arm species; here, we can refer to miktoarm stars, which can be subdivided into three groups: compositional miktoarm stars, miktoarm stars with irregular molecular-weight arms or end-functionalized miktoarm stars. A further classification of the star-like system is based on the character of the core used. We can describe the system as comprising small compound core-structured stars, macromolecule corestructured stars or network core-structured stars. Finally, star-like systems can also be classified from the point of view of the location of the functional group in the star-like system. We can therefore refer to core-functionalized, armfunctionalized or end-arm-functionalized stars. 
A

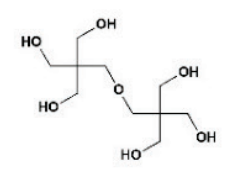

B

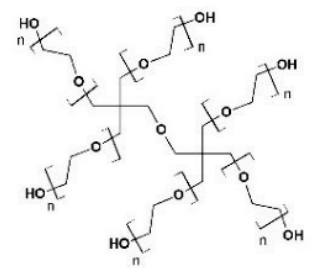

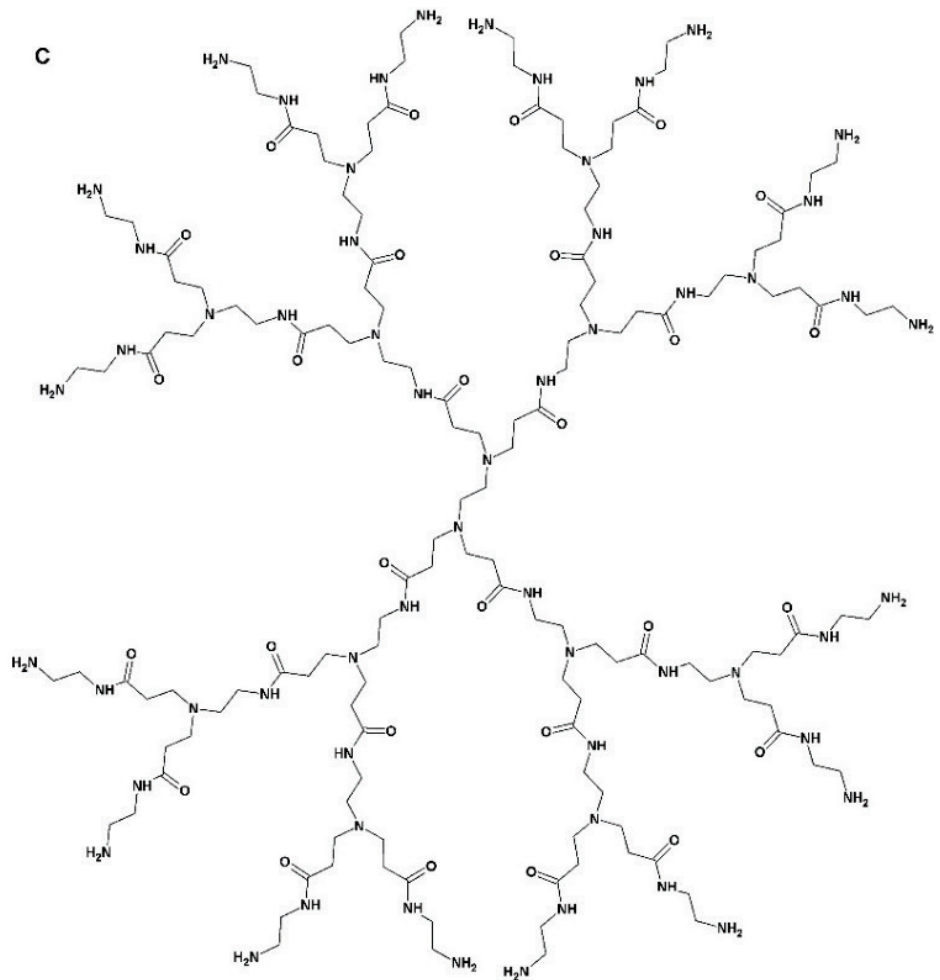

Fig. 1. The most popular cores for star-like polymer carriers: A - dipentaerythritol, B - 6arm-PEG, C - PAMAM (G2), D - bis-MPA (G3).

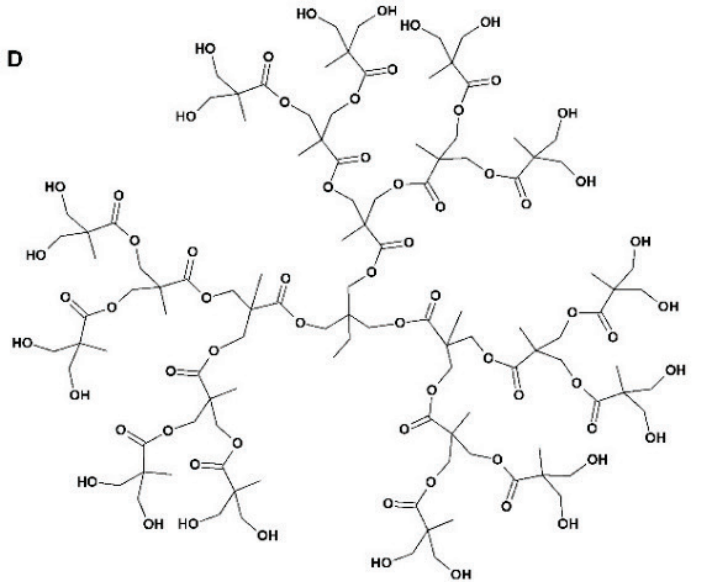

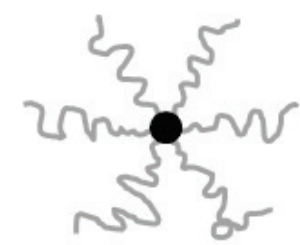

Homopolymer

star

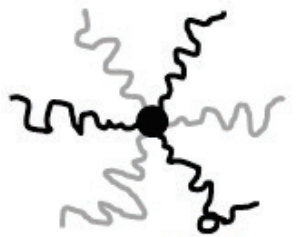

Compositional miktoarm star

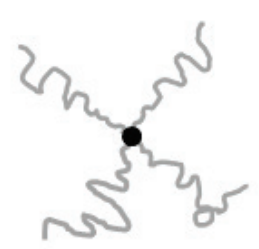

Small compound core-structured star

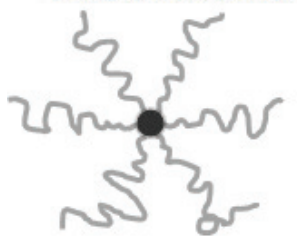

Core-functionalized star

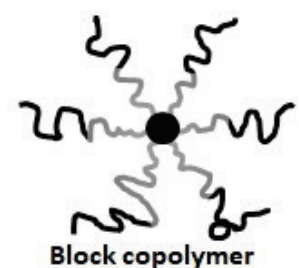

star
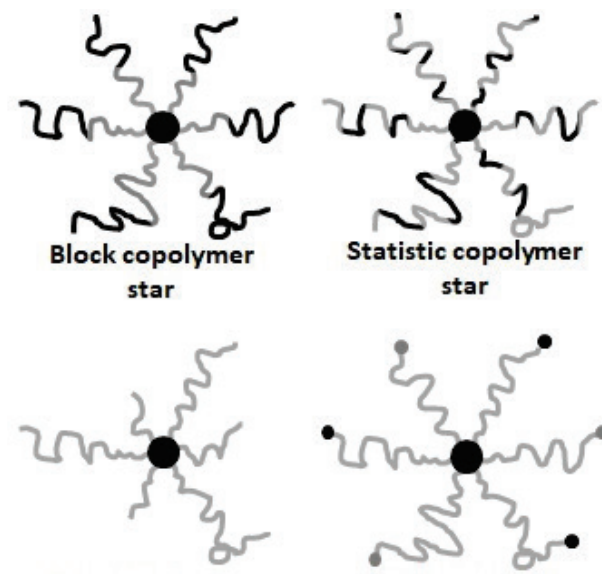

MW miktoarm

star

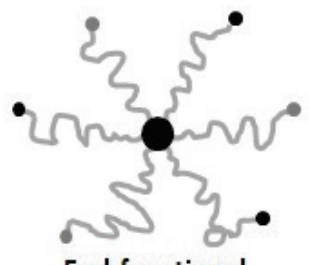

End-functioanl

miktoarm star

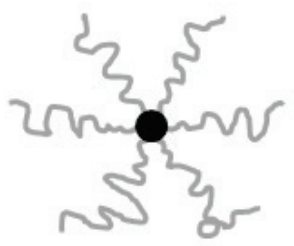

Macromolecule core-structured star

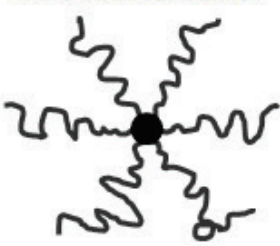

Arm-functionalized star

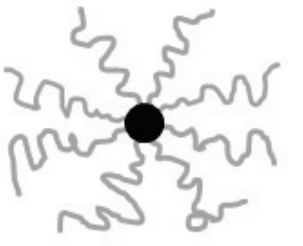

Network

core-structured star

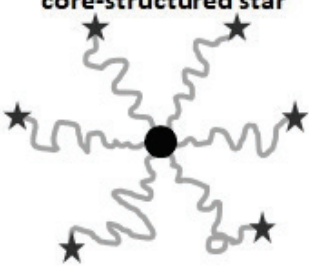

End-functionalized

star
Fig. 2. Classification of star-like polymers based on various points of view (figure adopted from Ren et al. 2016). 


\section{Star-like polymers based on PEG}

PEG is a hydrophilic synthetic polymer widely used as a water-soluble drug carrier or a surface modifier of supramolecular drug carriers such as micelles, liposomes and nanoparticles (Lammers et al. 2008, Tran et al. 2017). The advantage of PEG carriers is their chemical stability under neutral conditions, non-toxicity, and good biocompatibility, while the main drawback of these polymer carriers is the limited number of functional groups for drug molecule attachment. PEG does not have any functional group along the polymer chain. Therefore, the main-chain end groups are the only option for drug conjugation. The hydroxyl end groups, derived directly from the polymerization process of ethylene glycol, can be used directly for drug coupling or the hydroxyl group can be transformed into various functional groups (e.g. amino groups, propargyls, azides, aldehydes, bromo groups, mesylates, succinimido succinates) (Tekade et al. 2009) by a post-polymerization procedure and used for drug conjugation. Another way in which the number of functional groups in the polymer backbone can be increased is through the synthesis of PEG-based multiblocks, e.g. PEG blocks can be connected with oligopeptide "linkages," enabling the attachment of various active molecules (Pechar et al. 2000).

One of the most important uses of PEG is as a shielding agent for branched polymers, nanoparticles or proteins. This procedure is called pegylation, a term first used by Davis and Abuchowski in the case of albumin and catalase in the $1977 \mathrm{~s}$. The method represented a significant milestone, opening the way for scientists to modify proteins without losing their biological activity (Abuchowski et al. 1977a, Abuchowski et al. 1977b) Nowadays, pegylation is also a common approach to coating hydrophobic drug carriers in order to achieve solubilization or to reduce their side effects, which determine their toxicity in healthy tissues. One of the mostly used dendritic cores, PAMAM dendrimer, was used for star polymer production with PEG arms (Luong et al. 2016). The amino groups on the surface of the dendritic core have positive charges and, as a result, PAMAM shows a degree of cytotoxicity and/or hemolytic toxicity (Malik et al. 2000). Pegylation of some of the amino groups on the surface of the PAMAM core helps to prolong the circulation time of such star-like systems in the body due to the decreased reticuloendothelial system uptake. Pegylated PAMAM dendrimers also have higher anticancer drug loading and controlled drug release properties for efficient tumor treatment when compared to unmodified PAMAM dendrimers (Luong et al. 2016). The schematic structure of this star-like system is shown in Figure 3.

In order to substitute the PAMAM core, PEG-based cores were synthesized. These dendrons showed almost no toxicity and offered the possibility of carrying biologically active compounds on their surface (Berna et al. 2006). These dendrons were prepared with various end-group functionalities, 2-4 amino groups, with molecular weights ranging from 1,300-4,000 $\mathrm{g} \cdot \mathrm{mol}^{-1}$ and in high purity. To ensure that these systems can enter cells, fluorescence-labeled dendrons were synthesized and cellular uptake was observed. Dendrons with higher molecular weights and higher functionality showed faster uptake than that of smaller ones. Amphotericin B was attached to these dendrons and the conjugate was evaluated in vitro for drug release and cytotoxicity (Sedlák et al. 2008).

Branched PEG-based systems can also be synthesized by adding a branching linker to the PEG. This approach is represented by aspartic acid-based cores shielded with PEGs $\left(40,000 \mathrm{~g} \cdot \mathrm{mol}^{-1}\right)$. Cytosine arabinoside (cytarabine, ara-C) was conjugated to these carriers and evaluated for its biological characteristics (Choe et al. 2002). The conjugation of ara-C to the described star polymer prolonged the circulation of the carried drugs and showed higher accumulation of ara-C in tumor tissue due to the EPR.

Additional promising polymeric materials for biomedical applications include carriers based on hyperbranched polyglycerols, which are used as a core, and PEG, which is used as the shell of the star-like system. Hyperbranched polyglycerols are biocompatible, can be easily modified and can be designed to be biodegradable by incorporating biodegradable moieties such as ketals, esters and disulfides (Son et al. 2015, Hu et al. 2012, Shenoi et al. 2012).

Nowadays, combination therapy has become a standard in oncology. Moreover, star-like systems with a combination of two or more drugs have been reported. For example, a dendritic scaffold based on polyglycerol, decorated with PEG and equipped with a combination of two cytostatic drugs (doxorubicin (dox) and paclitaxel) has been reported and evaluated by Baabur-Cohen et al. (Baabur-Cohen et al. 2017).

\section{Star-like polymers based on pHPMA}

Copolymers based on HPMA (pHPMA), such as carriers of cytostatics, have been studied for almost the 
last four decades. The advantage of pHPMA is the possibility of introducing various functional groups directly into the polymer backbone through the copolymerization of HPMA with suitable comonomers. This enables attachment of the low-molecular-weight drug along the polymer chain by either cleavable or non-cleavable bonds, i.e. hydrazone or amidic bonds. The polymer carriers based on pHPMA show very good biocompatibility, non-immunogenic properties and no toxicity in many biological studies (Ulbrich et al. 2016).
A

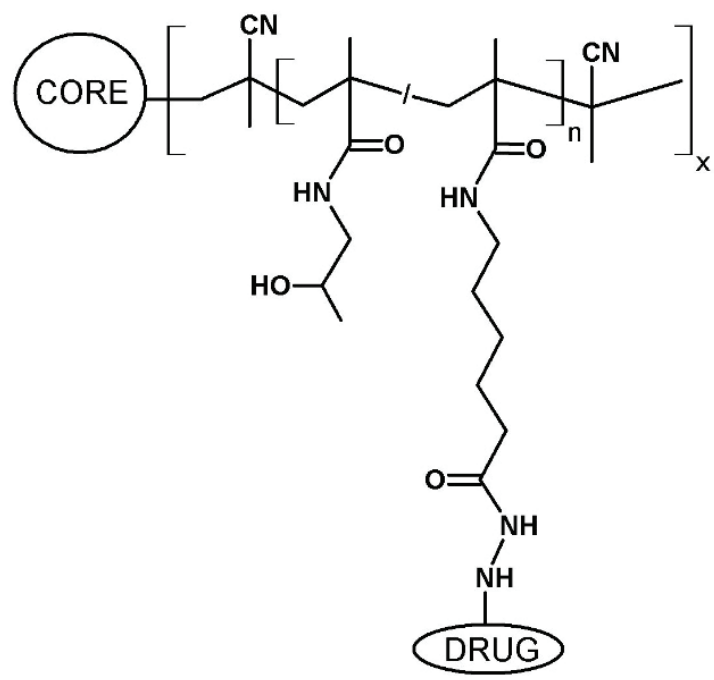

B

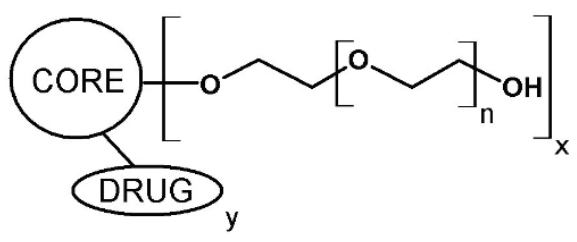

C

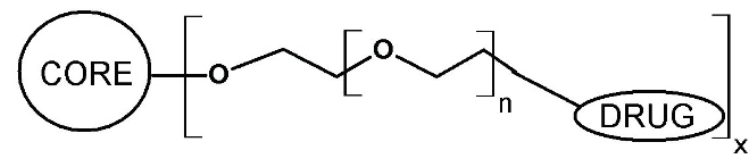

Fig. 3. Schematic structures of representative star-like drug carriers based on pHPMA or PEG: A - star-like pHPMA carrier, B - star-like PEG carrier with drug attached to the core, $\mathrm{C}$ - star-like PEG carriers with drug bonded to the polymer arms.

The first star-like pHPMA-based carrier was synthesized by Wang et al. (2000) using semitelechelic linear pHPMA-COOH $\left(M_{n}=5,400\right)$, prepared by freeradical polymerization, and subsequent activation of the carboxyl group to NHS. This semitelechelic copolymer was subsequently grafted onto PAMAM dendrimers (G2-G4, 16-64 amino groups). Non-degradable star-like polymer carriers with molecular weights ranging from 20,000-160,000 g. mol ${ }^{-1}$ were synthesized by amidic coupling. For the next 20 years or so, such nondegradable or biodegradable star-like polymer conjugates based on PAMAM cores and PHPMA copolymer arms were synthesized by free-radical polymerization with various biodegradable spacers between the PAMAM core and the pHPMA arms (e.g. oligopeptide sequences, disulfides) (Etrych et al. 2011a) and various stimulussensitive linkers between the carried drugs (dox, pirarubicin, docetaxel) and the star polymer (oligopeptide sequences, hydrazon bond) (Etrych et al. 2011b, Etrych et al. 2015, Nakamura et al. 2015). These star polymers represented one of the most promising systems in anticancer therapy, especially in the treatment of solid tumors. The schematic structure of the pHPMA-based star-like system is shown in Figure 3. Most attention has been paid to star-like polymer conjugates with polymer arms with an $M_{w}$ in the range of $20,000-30,000 \mathrm{~g} \cdot \mathrm{mol}^{-1}$ and with conjugates of an $M_{w}$ in the range of 100,000$1,000,000 \mathrm{~g} \cdot \mathrm{mol}^{-1}$ (Etrych et al. 2011a, Etrych et al. 2011b). Several in vivo studies have confirmed that the optimal molecular weight of non-biodegradable HPMAbased star-like systems with the highest antitumor activity and the best drug accumulation in tumors is between 200,000 and $600,000 \mathrm{~g} \cdot \mathrm{mol}^{-1}$ (Etrych et al. 2011b). Star-like carriers based on pHPMA copolymers are much more effective than their linear versions of polymer carriers in terms of therapeutic activity, which corresponds to higher drug accumulation in the solid tumor. Concurrently, degradable star-like pHPMA carriers were studied due to easier and faster elimination from the organism (Etrych et al. 2011b). Degradable starlike carriers based on PAMAM cores were synthesized by incorporating a cleavable linker between the PAMAM core and the HPMA polymeric arms. Two different types of biodegradable spacers were incorporated into these systems: either a reductively cleavable spacer (disulfide) or an enzymatically cleavable spacer (tetrapeptide GlyPheLeuGly) (Kostka and Etrych 2016). The cleavability of the disulfide or GlyPheLeuGly linkers and conjugate degradation do not seem to substantially influence the anti-tumor effect of the star polymer 
conjugates. The final anti-tumor efficacy, represented as the percentage of long-term survivors, was comparable when a lower dose of $5 \mathrm{mg}$ dox eq. $/ \mathrm{kg}$ was used of both non-degradable and biodegradable disulfide-containing star polymers, while slightly better efficacy was observed with a non-cleavable form of the polymeric drug when a higher dose $(10 \mathrm{mg}$ dox eq. $/ \mathrm{kg})$ was used. Similar experiments conducted with a biodegradable star conjugate containing enzymatically cleavable GlyPheLeuGly sequences showed an impressive treatment efficacy of up to $100 \%$ long-term survivors (LTS) in a group of mice treated with a dose of $10 \mathrm{mg}$ dox eq. $/ \mathrm{kg}$, and an efficacy of $60 \%$ LTS was observed in a group treated with a dose of $5 \mathrm{mg}$ dox eq. $/ \mathrm{kg}$ (Etrych $e t$ al. 2011b, Etrych et al. 2011c)

Another biodegradable star-like system based on pHPMA copolymers was described by Kostková et al. (Kostková et al. 2017). Here, the non-degradable PAMAM core was substituted with a biodegradable dendritic core based on polyesters (bis-MPA). For synthesis, semitelechelic linear polymers were prepared by free-radical polymerization and a controlled polymerization technique, radical reversible addition fragmentation chain transfer polymerization (RAFT). Linear arms were grafted onto the bis-MPA core through aminolytic reaction. These systems were well defined, with dispersity below $1.3(\bigoplus<1.3)$ compared to the abovedescribed PAMAM-based system, which showed a dispersity of approximately 1.8. These carriers were tested for biodegradability in aqueous buffers and also in human plasma with a half-life of 6 days in buffers (pH 7.4) and 3 days in human plasma. The half-life was estimated to be $50 \%$ of the released linear polymer from the star-like system.

A new generation of pHPMA star-like carriers based on the PAMAM core was introduced with a controlled polymerization technique, mainly RAFT. This step reduced the dispersity of star-like carriers from 1.8 to below 1.2 (Chytil et al. 2015).

In summary, PEG is a suitable shielding agent for hydrophobic molecules. It is commercially available in various modifications and is already FDA-approved for human medicine and use in pharmacy. Many various hyperbranched or star-like polymer conjugates with minimized side effects have been synthesized and reported. pHPMA seems to be a promising alternative to PEG. It can also be used as a shielding agent or carrier of diagnostic or drugs attached directly to the pHPMA copolymer backbone.

\section{Biopharmaceutical evaluation of star-like systems}

The use of polymers for drug delivery and targeting has shown significant potential, particularly in increasing drug safety and reducing drug-associated toxicity to non-targeted organs and tissues. As we already mentioned above, over the past four decades, biomedical research has focused on developing technologies for various clinical uses. One of the most promising and efficient systems in diagnostic and therapeutic uses is that of carriers based on dendrimers. In this part of the review, we summarize the biological evaluation of star-like systems, especially biodistribution studies.

To follow the biodistribution of star-like carriers in a living organism, a suitable label must be incorporated into such a system. It has been reported that a system can be labeled with radioisotopes (Kojima et al. 2010, (Hamilton et al. 2016) or fluorescent dye (Chytil et al. 2013, Hoffmann et al. 2012). Three different systems, based on either hyperbranched polyglycerols, a PAMAM core shielded with PEG or a PAMAM core shielded with pHPMA, were selected for a comparison of their biodistribution.

Hamilton et al. (2016) synthesized and evaluated biodegradable systems based on hyperbranched polyglycerols with a molecular mass of 65 or $637 \mathrm{~kg} \cdot \mathrm{mol}^{-1}$ and a corresponding $R_{\mathrm{h}}$ of 2.7 or $7.7 \mathrm{~nm}$, respectively. These systems were radiolabeled with tritium so as to follow the fate of the carrier in the body of healthy mice. Studies on organ accumulation and biodistribution have indicated a size-dependent accumulation, likely due to phagocytic uptake in the RES system, in the liver and spleen. Animals were injected with a single dose of $43 \mathrm{mg} \cdot \mathrm{kg}^{-1}$ and less than $1 \%$ of the injected dose per gram of organ tissue was found in pancreas, brain and femoral muscle over the experiment time (144 h). Between $1 \%$ and $5 \%$ of the injected dose per gram of organ tissue was found for all systems in the spleen, kidney, heart and lung. The highest accumulation was shown by the largest star-like system $(7.7 \mathrm{~nm})$ in the liver, wherein after $110 \mathrm{~h} 13 \%$ of the injected dose per gram of tissue was found.

Similarly, a system based on a PAMAM core and a PEG shell was evaluated for biodistribution by Kojima et al. (2010). They synthesized three different systems with various molecular masses. The first two systems were based on the G4 generation of PAMAM dendrimers and the shell of these star-like systems was 
generated using PEG with different lengths of the polymer chain (PEG 2,000 or PEG $5,000 \mathrm{~g} \cdot \mathrm{mol}^{-1}$ ). The third system was based on the G5 generation of PAMAM dendrimers shielded with PEG 2,000 $\mathrm{g} \cdot \mathrm{mol}^{-1}$. The schematic structure is shown in Figure 4. The molecular masses of these systems were calculated to be: G4-Peg2k, $162 \mathrm{~kg} \cdot \mathrm{mol}^{-1}$; G4-Peg5k, $334 \mathrm{~kg} \cdot \mathrm{mol}^{-1}$; and G5-Peg2k, $284 \mathrm{~kg} \cdot \mathrm{mol}^{-1}$. The biodistribution of these systems was evaluated by radiolabeling with ${ }^{111} \mathrm{In}$ and the injected dose was $1.5 \mu \mathrm{Ci}$ of ${ }^{111} \mathrm{In}$ (approximately $2 \mu \mathrm{g}$ in $200 \mu \mathrm{l}$ of PBS buffer). The authors concluded that PEG coating of the PAMAM core increased the circulation time of the system in the bloodstream approximately fivefold. The distribution over selected organs, such as the liver, spleen, kidney, lung, heart and bone, can be seen in
Figure 4, wherein these systems are compared. The biodistribution of pegylated dendrimers was significantly different from that determined for the non-pegylated dendrimers. Pegylation induced prolonged blood circulation and prevented accumulation in normal organs including the kidneys and the liver. After $24 \mathrm{~h}$ following injection, more than $25 \%$ of the injected dose remained circulating in the blood independently of the length of PEG used. The organ with the highest accumulation level was the lung in all cases. Here, after $1 \mathrm{~h}$ almost $15 \%$ of the injected dose was estimated and after $24 \mathrm{~h}$ the level decreased to $8-10 \%$ of the injected dose. In the liver, less than $8 \%$ of the injected dose was observed independently of the time following injection.
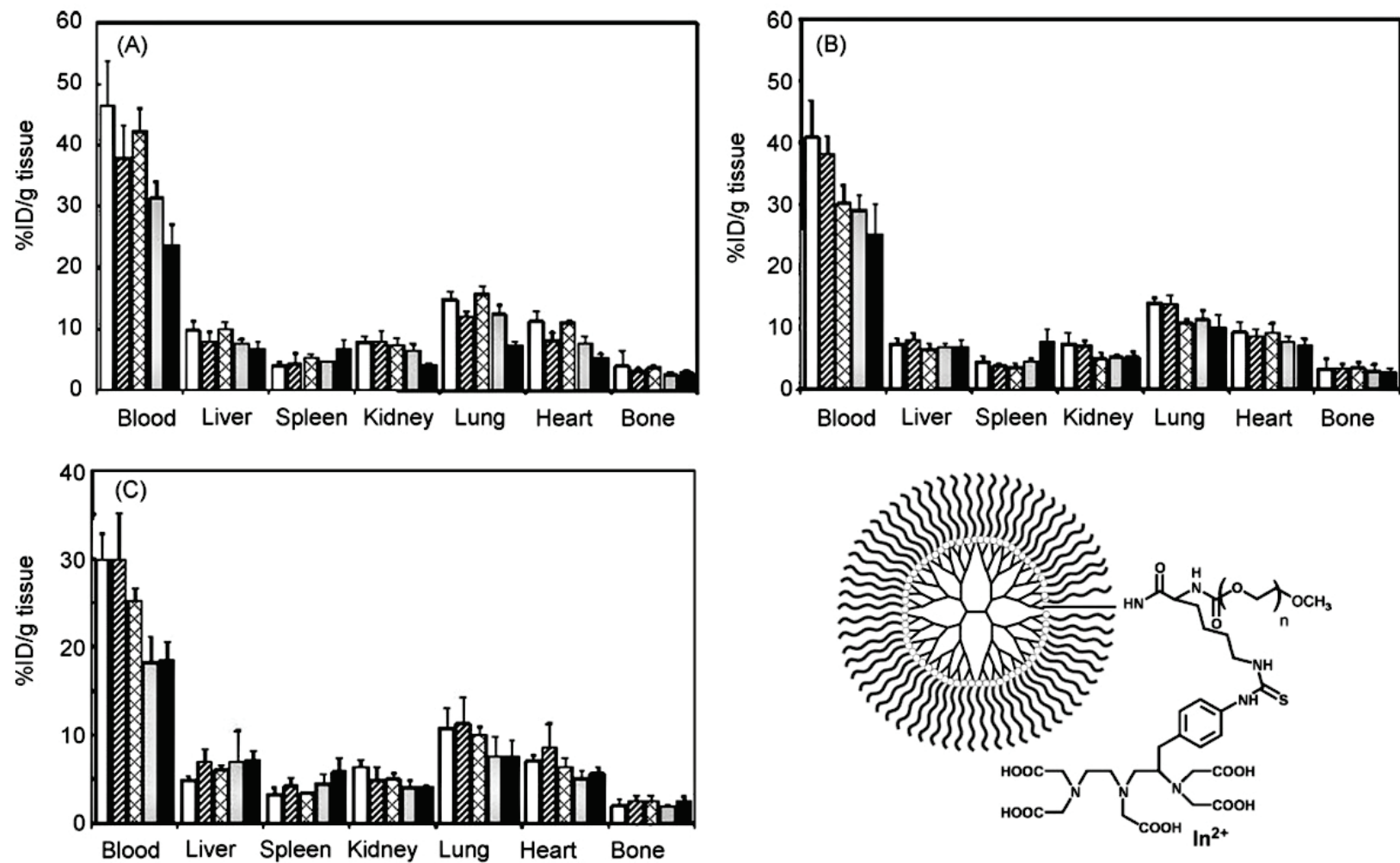

Fig. 4. Biodistributions of (A) PEG2k-Lys-PAMAM (G5), (B) PEG5k-Lys-PAMAM (G4), (C) PEG2k-Lys-PAMAM (G4) and the structure of the studied polymer carrier. The \%ID/g tissue after $0.25 \mathrm{~h}$ (white bars), $1 \mathrm{~h}$ (hatched bars), $3 \mathrm{~h}$ (cross-hatched bars), $6 \mathrm{~h}$ ( $\mathrm{gray}$ bars) and $24 \mathrm{~h}$ (black bars) is shown. The figure is modified and adapted from (Kojima et al. 2010).

Using pegylated PAMAM dendrimers as the drug carrier, Zhu et al. (2010) synthesized and characterized a series of dox-bearing polymer conjugates with different pegylation degrees and drug conjugation strategies. Both the pegylation degree and the drug conjugation strategy were found to affect the in vitro release, in vitro cytotoxicity, and cellular uptake. The acid-sensitive dox release determined the in vitro cytotoxicity against SKOV-3 cells. Mechanistic studies revealed that the dox polymer conjugates were internalized by SKOV-3 cells via clathrin-mediated endocytosis, which ensured their localization in the acidic cellular compartments, subsequent release of dox from PEG-PAMAM-cis-aconityl-dox (PPCD) conjugates, and final drug penetration into the nucleus. In vivo fluorescence imaging analysis of the biodistribution 
demonstrated that conjugates with 20 molecules of PEG $5 \mathrm{~kg} \cdot \mathrm{mol}^{-1}$ attached to PAMAM-G4, with a hydrodynamic size of $16 \mathrm{~nm}$, which accumulated at the tumor site the most efficiently. By increasing the degree of pegylation from four to 20 PEG chains per PAMAM core, accumulation at the tumor site almost doubled. Conversely, accumulation in other organs, such as the heart, liver, spleen, lung and kidneys, significantly decreased.

The star-like system based on PAMAM dendrimers decorated with pHPMA copolymers and evaluated for biodistribution has been reported by Pola et al. (2016), Hoffmann et al. (2012), Chytil et al. (2013). In all of these publications, star-like systems were evaluated using fluorescence-labeled carriers in living animals and also in extracted organs. These systems varied in molecular weight from 170 to $200 \mathrm{~kg} \cdot \mathrm{mol}^{-1}$ and also in different linkers used for the model drug attachment. (Chytil et al. (2013) reported the dependence of the accumulation and distribution of the model drug on the $\mathrm{pH}$-sensitive linker used for its attachment to the polymer backbone. It was shown that accumulation at the tumor site can be controlled well by using a linker for the $\mathrm{pH}$ trigger release of the model drug. Hoffmann et al. (2012) reported a similar star-like system of a PAMAM dendrimer core and a pHPMA copolymer in the shell. The non-degradable star polymer carriers were labeled with the near-infrared fluorescent dye DY-782. The authors reported that the dye showed minimal fluorescence retention in organs and the skin and was therefore suitable for in vivo evaluation of biodistribution in mice. Tested animals were inoculated with two tumors, DLD-1 and HT-29, on the left and right sides of the back. Accumulation in both tumors was preferential when compared to the rest of the body. Total accumulation represented by normalized fluorescent intensity (NFI) for both tumors (0.07) was almost double that of kidneys (0.035), four times higher in the case of the liver, lung and testes $(\mathrm{NFI}=0.015)$, and seven times higher when compared to the heart and spleen $(\mathrm{NFI}=0.01)$.

To summarize this part of the paper, we can state that the biodistribution of all the above-described star-like carriers is quite similar and beneficial compared to lowmolecular-weight compounds or even to the linear carriers. In the case of star-like systems based on PAMAM dendritic cores, when we compare the fate of the carriers themselves, the biodistribution is almost independent on the type of hydrophilic copolymer used in the shielding layer, namely PEG or pHPMA. Furthermore, from this point of view, all of the abovementioned systems showed superior accumulation in tumor tissue compared to the rest of the body.

\section{Conclusions}

Several synthetic approaches to the advanced synthesis of star-like polymer-based drug carriers have been described with the aim of discussing the relationship between the structure and physico-chemical and biological characteristics of the star polymer systems. Indeed, the application of these star polymers as nanomedicines in the therapy or diagnosis of neoplastic diseases has been described in detail, showing the potential of these water-soluble polymer systems. We can conclude that star-like polymers are highly interesting polymer carriers suitable for further preclinical development.

\section{Conflict of Interest}

There is no conflict of interest.

\section{Acknowledgements}

This work was supported by the Ministry of Education, Youth and Sports of CR within the National Sustainability Program II, Project BIOCEV-FAR LQ1604.

\section{References}

ABBINA S, VAPPALA S, KUMAR P, SIREN EMJ, LA CC, ABBASI U, BROOKS DE, KIZHAKKEDATHU JN: Hyperbranched polyglycerols: recent advances in synthesis, biocompatibility and biomedical applications. J Mater Chem B 5: 9249-9277, 2017.

ABUCHOWSKI A, VAN ES T, PALCZUK NC, DAVIS FF: Alteration of immunological properties of bovine serum albumin by covalent attachment of polyethylene glycol. Journal 252: 3578-3581, 1977.

ABUCHOWSKI A, MCCOY JR, PALCZUK NC, VAN ES T, DAVIS FF: Effect of covalent attachment of polyethylene glycol on immunogenicity and circulating life of bovine liver catalase. J Biol Chem 252: 3582-3586, 1977. 
BAABUR-COHEN H, VOSSEN LI, KRÜGER HR, ELDAR-BOOCK A, YEINI E, LANDA-ROUBEN N, TIRAM G, WEDEPOHL S, MARKOVSKY E, LEOR J, CALDERÓN M, SATCHI-FAINARO R: In vivo comparative study of distinct polymeric architectures bearing a combination of paclitaxel and doxorubicin at a synergistic ratio. J Control Release 257: 118-131, 2017.

BERNA M, DALZOPPO D, PASUT G, MANUNTA M, IZZO L, JONES AT, DUNCAN R, VERONESE FM: Novel monodisperse PEG - Dendrons as new tools for targeted drug delivery: Synthesis, characterization and cellular uptake. Biomacromolecules 71: 146-153, 2006.

CHOE YH, CONOVER CD, WU D, ROYZEN M, GERVACIO Y, BOROWSKI V, MEHLIG M, GREENWALD RB: Anticancer drug delivery systems: Multi-loaded N4-acyl poly(ethylene glycol) prodrugs of ara-C. II. Efficacy in ascites and solid tumors. $J$ Control Release 79: 55-70, 2002.

CHYTIL P, HOFFMANN S, SCHINDLER L, KOSTKA L, ULBRICH K, CAYSA H, MUELLER T, MÄDER K, ETRYCH T: Dual fluorescent HPMA copolymers for passive tumor targeting with $\mathrm{pH}$-sensitive drug release II: Impact of release rate on biodistribution. J Control Release 172: 504-512, 2013.

CHYTIL P, KOZIOLOVÁ E, JANOUŠKOVÁ O, KOSTKA L, ULBRICH K, ETRYCH T: Synthesis and properties of star HPMA copolymer nanocarriers synthesised by RAFT polymerisation designed for selective anticancer drug delivery and imaging. Macromol Biosci 15: 839-850, 2015.

CHYTIL P, ŠÍROVÁ M, KOZIOLOVÁ E, ULBRICH K, ŘÍHOVÁ B, ETRYCH T: The Comparison of in vivo properties of water-soluble HPMA-based polymer conjugates with doxorubicin prepared by controlled RAFT or free radical polymerization. Physiol Res 64 (Suppl 1): S41-S49, 2015.

ETRYCH T, KOVÁŘ L, STROHALM J, CHYTIL P, ŘÍHOVÁ B, ULBRICH K: Biodegradable star HPMA polymerdrug conjugates: Biodegradability, distribution and anti-tumor efficacy. J Control Release 154: 241-248, 2011.

ETRYCH T, STROHALM J, CHYTIL P, ČERNOCH P, STAROVOYTOVA L, PECHAR M, ULBRICH K: Biodegradable star HPMA polymer conjugates of doxorubicin for passive tumor targeting. Eur J Pharm Sci 42: 527-539, 2011.

ETRYCH T, STROHALM J, SIROVA M, TOMALOVA B, ROSSMANN P, RIHOVA B, ULBRICH K, KOVAR M: High-molecular weight star conjugates containing docetaxel with high anti-tumor activity and low systemic toxicity in vivo. Polym Chem 6: 160-170, 2015.

ETRYCH T, ŠUBR V, STROHALM J, ŠÍROVÁ M, ŘÍHOVÁ B, ULBRICH K: HPMA copolymer-doxorubicin conjugates: The effects of molecular weight and architecture on biodistribution and in vivo activity. $J$ Control Release 164: 346-354, 2012.

ETRYCH T, STROHALM J, CHYTIL P, ŘÍHOVÁ B, ULBRICH K: Novel star HPMA-based polymer conjugates for passive targeting to solid tumors. J Drug Target 19: 874-889, 2011.

HAMILTON JL, IMRAN UL-HAQ M, ABBINA S, KALATHOTTUKAREN MT, LAI BFL, HATEF A, UNNIAPPAN S, KIZHAKKEDATHU JN: In vivo efficacy, toxicity and biodistribution of ultra-long circulating desferrioxamine based polymeric iron chelator. Biomaterials 102: 58-71, 2016.

HOFFMANN S, VYSTRČILOVÁ L, ULBRICH K, ETRYCH T, CAYSA H, MUELLER T, MÄDER K: Dual fluorescent HPMA copolymers for passive tumor targeting with $\mathrm{pH}$-sensitive drug release: Synthesis and characterization of distribution and tumor accumulation in mice by noninvasive multispectral optical imaging. Biomacromolecules 13: 652-663, 2012.

HRUBÝ M, FILIPPOV SK, ŠTĚPÁNEK P: Supramolecular structures and self-association processes in polymer systems. Physiol Res 65 (Suppl 2): S165-S178, 2016.

HU M, CHEN M, LI G, PANG Y, WANG D, WU J, QIU F, ZHU X, SUN J: Biodegradable hyperbranched polyglycerol with ester linkages for drug delivery. Biomacromolecules 13: 3552-3561, 2012.

JONES RG, KITAYAMA T, HELLWICH KH, HESS M, JENKINS AD, KAHOVEC J, KRATOCHVÍL P, MITA I, MORMANN W, OBER CK, PENCZEK S, STEPTO RFT, THURLOW K, VOHLÍDAL J, WILKS ES: Source-based nomenclature for single-strand homopolymers and copolymers (IUPAC Recommendations 2016). Pure Appl Chem 88: 1073-1100, 2016.

KOJIMA C, REGINO C, UMEDA Y, KOBAYASHI H, KONO K: Influence of dendrimer generation and polyethylene glycol length on the biodistribution of PEGylated dendrimers. Int J Pharm 383: 293-296, 2010. 
KOSTKA L, ETRYCH T: High-molecular-weight HPMA-based polymer drug carriers for delivery to tumor. Physiol Res 65 (Suppl 2): S179-S190, 2016.

KOSTKOVÁ H, SCHINDLER L, KOTRCHOVÁ L, KOVÁŘ M, ŠÍROVÁ M, KOSTKA L, ETRYCH T: Star polymer-drug conjugates with $\mathrm{pH}$-controlled drug release and carrier degradation. $J$ Nanomater 2017: Article ID 8675435, 2017.

LAMMERS T, HENNINK WE, STORM G: Tumour-targeted nanomedicines: Principles and practice. Br J Cancer 99: 392-397, 2008.

LAPIENIS G: Functionalized star-shaped polymers having PEO and/or polyglycidyl arms and their properties. Polymer (Guildf) 50: 77-84, 2009.

LEARSCH R, MIYAKE GM: Arm-first synthesis of star polymers with polywedge arms using ring-opening metathesis polymerization and bifunctional crosslinkers. J Polym Sci Part A Polym Chem 56: 732-740, 2018.

LI C, WALLACE S: Polymer-drug conjugates: Recent development in clinical oncology. Adv Drug Deliv Rev 60: 886-898, 2008.

LIDICKÝ O, ŠÍROVÁ M, ETRYCH T: HPMA copolymer-based polymer conjugates for the delivery and controlled release of retinoids. Physiol Res $\mathbf{6 5}$ (Suppl 2): S233-S241, 2016.

LUONG D, KESHARWANI P, DESHMUKH R, MOHD AMIN MCI, GUPTA U, GREISH K, IYER AK: PEGylated PAMAM dendrimers: Enhancing efficacy and mitigating toxicity for effective anticancer drug and gene delivery. Acta Biomater 43: 14-29, 2016.

MAEDA H, MATSUMURA Y: Tumoritropic and lymphotropic principles of macromolecular drugs. Crit Rev Ther Drug Carrier Syst 6: 193-210, 1989.

MALIK N, WIWATTANAPATAPEE R, KLOPSCH R, LORENZ K, FREY H, WEENER JW, MEIJER EW, PAULUS W, DUNCAN R: Dendrimers: Relationship between structure and biocompatibility in vitro, 125 and preliminary studies on the biodistribution of I-labelled polyamidoamine dendrimers in vivo. $J$ Control Release 65: 133-148, 2000.

NAKAMURA H, KOZIOLOVÁ E, ETRYCH T, CHYTIL P, FANG J, ULBRICH K, MAEDA H: Comparison between linear and star-like HPMA conjugated pirarubicin (THP) in pharmacokinetics and antitumor activity in tumor bearing mice. Eur J Pharm Biopharm 90: 90-96, 2015.

PECHAR M, ULBRICH K, ŠUBR V, SEYMOUR LW, SCHACHT EH: Poly(ethylene glycol) multiblock copolymer as a carrier of anti-cancer drug doxorubicin. Bioconjug Chem 11: 131-139, 2000.

POLA R, HEINRICH A, MUELLER T, KOSTKA L, MÄDER K, PECHAR M, ETRYCH T: Passive tumor targeting of polymer therapeutics: In vivo imaging of both the polymer carrier and the enzymatically cleavable drug model. Macromol Biosci 16: 1577-1582, 2016.

POLA R, JANOUŠKOVÁ O, ETRYCH T: The pH-dependent and enzymatic release of cytarabine from hydrophilic polymer conjugates. Physiol Res 65 (Suppl 2): S225-S232, 2016.

REN JM, MCKENZIE TG, FU Q, WONG EHH, XU J, AN Z, SHANMUGAM S, DAVIS TP, BOYER C, QIAO GG: Star polymers. Chem Rev 116: 6743-6836, 2016.

SEDLÁK M, DRABINA P, BÍLKOVÁ E, ŠIMU゚NEK P, BUCHTA V: New targeting system for antimycotic drugs: $\beta$-Glucosidase sensitive Amphotericin B-star poly(ethylene glycol) conjugate. Bioorganic Med Chem Lett 18: 2952-2956, 2008.

SHENOI RA, NARAYANANNAIR JK, HAMILTON JL, LAI BFL, HORTE S, KAINTHAN RK, VARGHESE JP, RAJEEV KG, MANOHARAN M, KIZHAKKEDATHU JN: Branched multifunctional polyether polyketals: Variation of ketal group structure enables unprecedented control over polymer degradation in solution and within cells. J Am Chem Soc 134: 14945-14957, 2012.

SON S, SHIN E, KIM BS: Redox-degradable biocompatible hyperbranched polyglycerols: Synthesis, copolymerization kinetics, degradation, and biocompatibility. Macromolecules 48: 600-609, 2015.

TEKADE RK, DUTTA T, GAJBHIYE V, JAIN NK: Exploring dendrimer towards dual drug delivery: pH responsive simultaneous drug-release kinetics. J Microencapsul 26: 287-296, 2009.

TRAN S, DEGIOVANNI PJ, PIEL B, RAI P: Cancer nanomedicine: a review of recent success in drug delivery. Clin Transl Med 6: 44, 2017. 
ULBRICH K, HOLÁ K, ŠUBR V, BAKANDRITSOS A, TUČEK J, ZBOŘIL R: Targeted drug delivery with polymers and magnetic nanoparticles: covalent and noncovalent approaches, release control, and clinical studies. Chem Rev 116: 5338-5431, 2016.

WANG D, KOPECKOVÁ JP, MINKO T, NANAYAKKARA V, KOPECEK J: Synthesis of starlike N-(2-hydroxypropyl)methacrylamide copolymers: potential drug carriers. Biomacromolecules 1: 313-319, 2000 .

WU W, WANG W, LI J: Star polymers: Advances in biomedical applications. Prog Polym Sci 46: 55-85, 2015. 